\title{
Application of chromosomal restriction endonuclease digest analysis for use as typing method for Clostridium difficile
}

\author{
P G H PEERBOOMS, ${ }^{*}$ P KUIJT,* D M MACLAREN $\dagger$ \\ From the *Department of Clinical Microbiology, Academisch Ziekenhuis Vrije Universiteit, and the \\ †Department of Medical Microbiology, Research Group for Commensal Infections, Vrije Universiteit, \\ Amsterdam, The Netherlands
}

SUMMARY The usefulness of restriction endonuclease analysis of chromosomal DNA as a typing method for Clostridium difficile was tested. Over four months all faecal samples were routinely cultured for $C$ difficile. DNA of all isolated strains was isolated and tested with the restriction endonuclease Hind III. The patterns obtained after electrophoresis in agarose gels seemed to be strain specific. Antibiotic susceptibility profiles agreed with the results of the restriction endonuclease analysis, though they were much less discriminating. Analysis of the results indicated that restriction endonuclease analysis is a suitable typing method for $C$ difficile, which may be very valuable in epidemiological studies where a highly discriminating typing method is needed.

Clostridium difficile is a pathogen associated with diarrhoea and (pseudomembranous) colitis, which occurs nearly always after antimicrobial treatment. $C$ difficile, however, can also be cultured from a low percentage of healthy subjects ${ }^{1}$ and from even higher percentages of asymptomatic inpatients. ${ }^{2} C$ difficile is also a common inhabitant of the gut in young children, apparently without causing disease. ${ }^{3}$

Some studies have shown that $C$ difficile is easily transmissible, evidenced by clustering of cases in wards in hospitals or in institutions. ${ }^{45}$ Likewise, the colonisation of neonates by $C$ difficile is now thought to originate from the environment and not from the vagina of the mother. ${ }^{6}$ The study of the epidemiology of $C$ difficile is, however, seriously hampered by the lack of sensitive and highly discriminating typing methods. Though different methods such as antibiogram typing. ${ }^{7}$ serotyping, ${ }^{8}$ typing by electrophoresis patterns of soluble cellular proteins with different modifications ${ }^{9-11}$ or phage and bacteriocin typing ${ }^{12}$ have been occasionally used with success, these methods are not always suitable for epidemiological studies, because they lack sensitivity or discriminating power, or because the required

Accepted for publication 27 November 1986 reagents are not commercially available. Restriction endonuclease analysis of chromosomal DNA of bacteria has been used successfully in epidemiological studies of Leptospira, ${ }^{13}$ Campylobacter, ${ }^{14}$ and Legionella. ${ }^{15}$ We therefore decided to investigate the suitability of this method for epidemiological studies of $C$ difficile.

\section{Material and methods}

ISOLATION OF $C$ difficile FROM FAECES

Over four months all faecal samples sent to our laboratory for culture on enteropathogenic bacteria were plated on a selective medium for $C$ difficile. The selective medium used was brain heart infusion agar (Difco), supplemented with $5 \%(\mathrm{v} / \mathrm{v})$ horse blood, $0 \cdot 1 \%(\mathrm{w} / \mathrm{v})$ sodium tauroglycocholate, cefoxitin (10 $\mathrm{mg} / \mathrm{l})$ and cycloserin $(250 \mathrm{mg} / \mathrm{l}) .^{1617}$ The identity of all suspected isolates was confirmed by standard identification methods. ${ }^{18}$

\section{CYTOTOXIN ASSAY}

All faecal samples and all isolated strains were tested for the presence of cytotoxin or the ability to produce cytotoxin. Vero cells (African green monkey kidney cells, Flow Laboratories) were used in this assay, which was performed by standard methods. ${ }^{19}$ 


\section{SUSCEPTIBILITY TESTING}

All isolates were tested for their susceptibility to nine different antibiotics by the broth microdilution method. The antibiotics tested were: chloramphenicol, rifampicin, penicillin G (Gist Brocades, Delft, The Netherlands), cefotoxitin (Merck, Sharp and Dohme), clindamycin (Upjohn), vancomycin (Eli Lilly), metronidazole (Rhône-Poulenc), ticarcillin (Beecham) and piperacillin (Lederle). All drugs were used as commercially available materials. Dilutions of antibiotics were made in supplemented brain heart infusion broth. ${ }^{18}$ The trays were stored until use at $-70^{\circ} \mathrm{C}$, and before inoculation they were prereduced for four hours in an anaerobic chamber. After inoculation with diluted overnight cultures grown in brain heart infusion broth, yielding an inoculum of about $10^{5}$ colony forming units (cfu) per well, the trays were incubated anaerobically for $\mathbf{4 0}$ hours.

The agar dilution method of susceptibility testing ${ }^{20}$ was used for confirmation of the results for three antibiotics: chloramphenicol, clindamycin, and penicillin G.

\section{FERMENTATION OF SORBITOL}

Fermentation of sorbitol was tested in peptone-yeast extract medium ${ }^{18}$ with $1 \%(\mathrm{w} / \mathrm{v})$ sorbitol. Tubes with $3 \mathrm{ml}$ of the sorbitol medium were inoculated with $100 \mu \mathrm{l}$ of turbid cultures (grown for 24 hours in brain heart infusion broth) of the strains to be tested, and incubated in an anaerobic chamber at $37^{\circ} \mathrm{C}$ for 48 hours, after which the $\mathrm{pH}$ was measured using a $\mathrm{pH}$ meter with a combination electrode (Russell, Helmstadt-Bargen, West Germany).

\section{PREPARATION OF CHROMOSOMAL DNA OF $C$ difficile STRAINS}

Essentially the same method as described by van Ketel et $a l^{15}$ was used. Bacterial cells were harvested from brain heart infusion broth cultures $(100 \mathrm{ml})$, grown anaerobically for 72 hours by centrifugation and resuspended in $2.5 \mathrm{ml}$ TES buffer $(150 \mathrm{mM}$ sodium chloride; $10 \mathrm{mM}$ Tris; $10 \mathrm{mM}$ sodium edetic acid; $\mathrm{pH} 8.0$ ). After incubation for 60 minutes at $37^{\circ} \mathrm{C}$ with lysozyme $(1 \mathrm{mg} / \mathrm{ml})$ cells were lysed by the addition of sodium dodecylsulfate (SDS) in a final concentration of $1 \%(w / v)$, followed by an incubation period of 10 minutes at $60^{\circ} \mathrm{C}$. The lysate was then incubated with ribonuclease $\mathbf{A}$ (Boehringer, Mannheim) in a final concentration of $100 \mu \mathrm{l} / \mathrm{ml}$ for 60 minutes at $37^{\circ} \mathrm{C}$, followed by digestion with proteinase $\mathrm{K}$ in a final concentration of $500 \mu \mathrm{g} / \mathrm{ml}$ for 60 minutes at $60^{\circ} \mathrm{C}$. After addition of sodium chloride to a final concentration of $1 \mathrm{M}$ the DNA was extracted with phenol-chloroform-isoamylalcohol (25:24:1) and precipitated with ethanol. The precipitated DNA was dissolved in saline-citrate buffer $(0.015 \mathrm{M}$ sodium chloride; $0.0015 \mathrm{M}$ trisodium citrate; $\mathrm{pH} \mathrm{7.0)}$ to yield a concentration of about $500 \mu \mathrm{g} / \mathrm{ml}$.

RESTRICTION ENZYME DIGESTION OF DNA AND GEL ELECTROPHORESIS

About $8 \mu \mathrm{g}$ DNA was digested with $8 \mathrm{U}$ of the restriction enzyme Hind III in buffer $(50 \mathrm{mM}$ sodium chloride; $10 \mathrm{mM}$ Tris; $10 \mathrm{mM}$ magnesium chloride; 1 $\mathrm{mM}$ dithiothreitol; $\mathrm{pH} \mathrm{7.5)}$ at $37^{\circ} \mathrm{C}$ for two hours. Digests were then electrophoresed for 22 hours at 30 $\mathrm{V}$ in a $0.7 \%$ agarose gel (electrophoresis buffer: 40 $\mathrm{mM}$ Tris; $20 \mathrm{mM}$ sodium acetate; $2 \mathrm{mM}$ sodium edetic acid; $6 \mu \mathrm{g} / \mathrm{ml}$ ethidium bromide; $\mathrm{pH} \mathrm{7 \cdot 7).} \mathrm{The} \mathrm{gel}$ $(20 \times 20 \mathrm{~cm})$ was then photographed with a Polaroid camera under ultraviolet illumination.

\section{Results}

During the study period 203 faecal samples were screened for the presence of $C$ difficile or its toxin. Thirty three specimens from 28 different patients were culture positive; only five of these samples were positive in the cytotoxin assay. As expected, samples from children aged less than one year were most often culture positive-16 of $29(55 \%)$. A second group of patients in whom $C$ difficile was commonly found were those receiving oral antibiotics for selective gut decontamination: seven of 19 patients $(37 \%)$ had a positive stool culture at least once during the study period. In the remaining group of patients only seven of 105 samples $(7 \%)$ were culture positive. In view of these data it is not surprising that clustering of patients with positive cultures occurred only in the paediatric wards, where also most patients undergoing selective decontamination of the gut were nursed. No other clustering was observed during surveillance.

Table 1 shows data about origin (ward and patient) and characteristics of the strains (toxin production, antibiogram, and restriction endonuclease pattern).

\section{ANTIBIOGRAM TYPING}

The minimum inhibitory concentration values of the isolates were uniform. Table 2 shows the typical susceptibility profiles. Differences in susceptibility of one dilution step were disregarded. All isolates were tested at least twice, and reproducibility was excellent, except for chloramphenicol and clindamycin, where occasionally irregular growth in isolated wells was observed. Therefore we repeated the susceptibility testing for chloramphenicol, clindamycin, and penicillin $G$ by an agar dilution method: reproducibility was good and the aberrant profiles were confirmed, though systematically lower minimum inhibitory concentration values were obtained for penicillin $\mathbf{G}$ and systematically higher minimum inhibitory concen- 
Table 1 Origin and characteristics of $C$ difficile strains

\begin{tabular}{|c|c|c|c|c|c|}
\hline Strain No & Case No & Ward & Toxin production & Antibiotic profile & Restriction type \\
\hline $4^{*}$ & 1 & $6 \mathrm{M}$ & + & I & A \\
\hline $6^{*}$ & 1 & $6 \mathrm{M}$ & + & i & A \\
\hline $7^{*}$ & 1 & $6 \mathrm{M}$ & + & I & A \\
\hline $10^{*}$ & 2 & $?$ & + & III & C \\
\hline $12^{*}$ & 3 & $?$ & + & II & D \\
\hline 15 & 4 & 20 & + & I & \\
\hline 16 & 5 & Outpatient & - & I & \\
\hline 17 & 6 & Outpatient & + & I & \\
\hline 18 & 7 & 40 & + & I & \\
\hline 19 & 8 & $10 \mathrm{M}$ & + & I & \\
\hline 20 & 9 & $6 \mathrm{M}$ & + & II & D \\
\hline 21 & 10 & $10 \mathrm{M}$ & + & I & B \\
\hline 22 & i1 & Outpatient & + & I & \\
\hline 23 & 12 & Outpatient & + & III & $\mathrm{C}$ \\
\hline 24 & 13 & $10 \mathrm{M}$ & + & I & B \\
\hline 25 & 14 & $8 \mathrm{~W}$ & + & i & B \\
\hline 26 & 15 & $10 \mathrm{~W}$ & + & I & \\
\hline 27 & 10 & $10 \mathrm{M}$ & + & III & $\mathrm{C}$ \\
\hline 28 & 16 & $9 \mathrm{~W}$ & - & I & \\
\hline 29 & 10 & $10 \mathrm{M}$ & + & I & B \\
\hline 30 & 8 & $10 \mathrm{M}$ & + & I & \\
\hline 31 & 17 & $10 \mathrm{M}$ & + & I & \\
\hline 32 & 18 & Outpatient & + & I & \\
\hline 33 & 19 & 40 & + & I & \\
\hline 34 & 17 & $10 \mathrm{M}$ & + & I & B \\
\hline 35 & 20 & $9 \mathrm{~W}$ & + & I & B \\
\hline 36 & 21 & 80 & + & I & \\
\hline 37 & 22 & 40 & + & I & \\
\hline 38 & 23 & $8 \mathrm{M}$ & + & I & \\
\hline 39 & 24 & Outpatient & + & I & \\
\hline 40 & 25 & $10 \mathrm{M}$ & + & I & B \\
\hline 41 & 26 & 40 & + & IV & E \\
\hline 42 & 17 & $10 \mathrm{M}$ & + & I & B \\
\hline 43 & 17 & $9 \mathrm{~W}$ & + & I & B \\
\hline 44 & 28 & Outpatient & + & I & B \\
\hline 45 & 29 & $10 \mathrm{M}$ & + & I & \\
\hline 46 & 26 & 40 & - & I & \\
\hline 47 & 10 & $10 \mathrm{M}$ & + & III & $\mathrm{C}$ \\
\hline
\end{tabular}

*Strains isolated prior to the study period.

tration values for chlor-amphenicol. It is obvious from these results that the discriminating power of antibiotyping for this set of isolates is low: only seven of 38 isolates $(18 \%)$ showed an aberrant profile.

FERMENTATION OF SORBITOL

Sorbitol fermentation tests using different broth bases and different $\mathrm{pH}$ indicators yielded results that were uninterpretable because of lack of clear cut positive or negative results. Finally, we measured the $\mathrm{pH}$ after incubation. Fig 1 shows that only quantitative differences in sorbitol fermentation exist between $C$ difficile strains.

\section{RESTRICTION ENDONUCLEASE ANALYSIS}

In a preliminary study three restriction endonucleases

Table 2 Susceptibility profiles of $38 \mathrm{C}$ difficile strains

\begin{tabular}{|c|c|c|c|c|c|c|}
\hline \multirow[b]{2}{*}{ Antibiotic tested } & \multicolumn{6}{|l|}{ Profile No* } \\
\hline & $I$ & $I I$ & $I I I I$ & $I V$ & Reference 21 & Reference 22 \\
\hline $\begin{array}{l}\text { Chloramphenicol } \\
\text { Rifampicin } \\
\text { Clindamycin } \\
\text { Vancomycin } \\
\text { Metronidazole } \\
\text { Cefoxitin } \\
\text { Ticarcillin } \\
\text { Piperacillin } \\
\text { Penicillin G } \\
\text { No of strains }\end{array}$ & $\begin{aligned} & \leqslant 0.5(4) \\
& \leqslant 0.06 \\
& 0.25(0.12) \\
& \leqslant 0.5 \\
& 0.35 \\
& 64 \\
& 4 \\
& 4 \\
& 1 \\
& 31\end{aligned}$ & $\begin{array}{l}\geqslant 16(\geqslant 128) \\
\leqslant 0 \cdot 06 \\
\geqslant 32(\geqslant 128) \\
\leqslant 0 \cdot 5 \\
0 \cdot 25 \\
64 \\
8 \\
4 \\
2 \\
2\end{array}$ & $\begin{aligned} & \leqslant 0.5(4) \\
& \leqslant 0.06 \\
& 0.25(0.12) \\
& \leqslant 0.5 \\
& 0.25 \\
& 64 \\
& 16 \\
& 8 \\
& 4 \\
& 4\end{aligned}$ & $\begin{array}{l}\leqslant 0.5 \quad(4) \\
\leqslant 0 \cdot 06 \\
\geqslant 32(\geqslant 128) \\
\leqslant 0 \cdot 5 \\
0.25 \\
32 \\
4 \\
2 \\
1 \\
1\end{array}$ & $\begin{array}{c}2-4 \\
\leqslant 0 \cdot 06 \\
4-8 \\
2-4 \\
0 \cdot 25-0 \cdot 5 \\
64-128 \\
16-64 \\
4-16 \\
1-4\end{array}$ & $\begin{array}{l}\leqslant 1 \\
\ldots 1 \\
\leqslant 1 \\
\leqslant 1 \\
\leqslant 1 \\
\quad 32-128 \\
\ldots \\
\cdots \\
\leqslant 1\end{array}$ \\
\hline
\end{tabular}

* Minimum inhibitory concentration values are in $\mathrm{mg} / \mathrm{l}$; values between parentheses are obtained by an agar dilution method. 


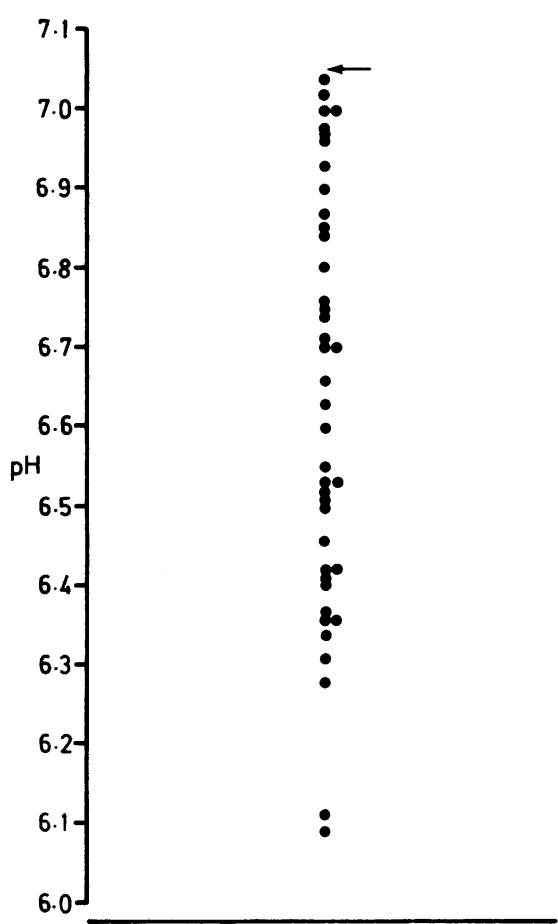

Fig 1 pH values afier 48 hours of incubation of strains in sorbitol fermentation broth: $\rightarrow$ designates $\mathrm{pH}$ of uninoculated hroth.

were tested on the DNA of a few $C$ difficile strains: EcoR I, BamH I, and Hind III. Only Hind III digestion of DNA resulted in discrete patterns after electrophoresis, whereas digestion was incomplete with EcoR I and even more so with BamH I. Hind III digestion of the DNA of three isolates (cases 4, 6, and 7) from three stool samples of one patient during an episode of pseudomembranous colitis yielded identical patterns, designated as restriction pattern type $A$, thus showing the reproducibility of the method (fig 2). Another 35 isolates were then analysed with this method. Fig 3 shows an example of patterns of randomly closen isolates. Inspection of all patterns after gel electrophoresis showed 22 different patterns. Ten isolates yielded completely similar patterns (restriction pattern type B, fig 4), and all these isolates were cultured from stool specimens of children. Nine of these children were patients in one of three paediatric wards. The tenth child was seen in the outpatient department; as a neonate this child had stayed two weeks in the maternity ward, four months earlier. A second group of four identical isolates (designated as restriction type C, fig 4) was found. These isolates showed a slightly lower susceptibility to penicillin G, ticarcillin, and piperacillin (antibiotic profile III).
Two of these isolates (cases 27 and 47) were isolated from the same patient (case 10) as were the two iden- 을 tical isolates (cases 21 and 29) of restriction pattern $\Rightarrow$ type B, indicating that this patient was colonised $\stackrel{\vec{S}}{+}$ alternately, or perhaps simultaneously, with two different strains. A last group of only two identical isolates was designated as restriction pattern type $D$ (fig 4). For comparison, a single isolate (restriction pattern type E; fig 4) is shown, as this shares the resistance against clindamycin but not against chloramphenicol with the two isolates of restriction pattern type D. All other strains showed unique electrophoresis patterns.

\section{Discussion}

Restriction endonuclease analysis of chromosomal DNA seems to be a suitable method for discriminating between individual strains of $C$ difficile. Our 을 results strongly suggest that each individual strain shows a unique restriction endonuclease pattern. The $c$ fact that groups of isolates with an aberrant profile coincide with groups with identical restriction endo- $\overrightarrow{0}$ nuclease patterns supports the validity of this

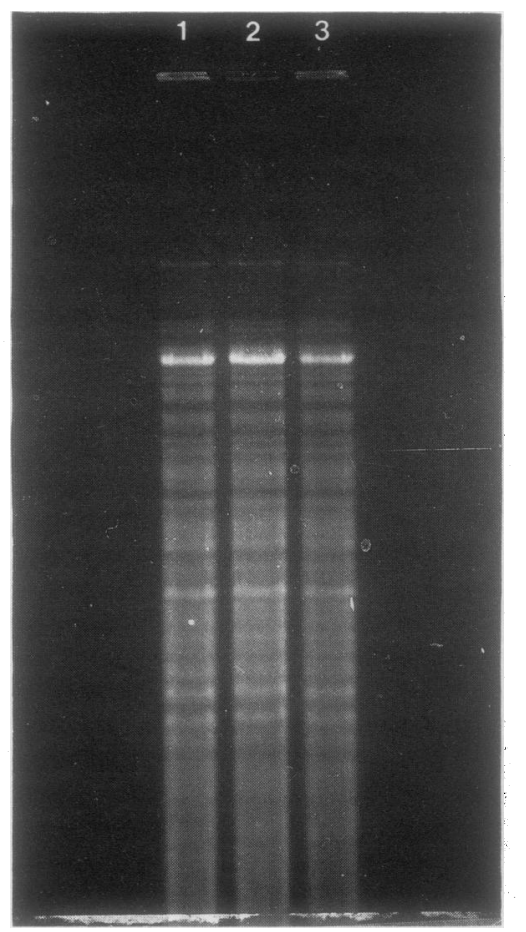

Fig 2 Agarose gel electrophoresis patterns of Hind III digests of chromosomal DNA. Lane 1: strain 4; lane 2: strain 6; lane 3: strain 7. 


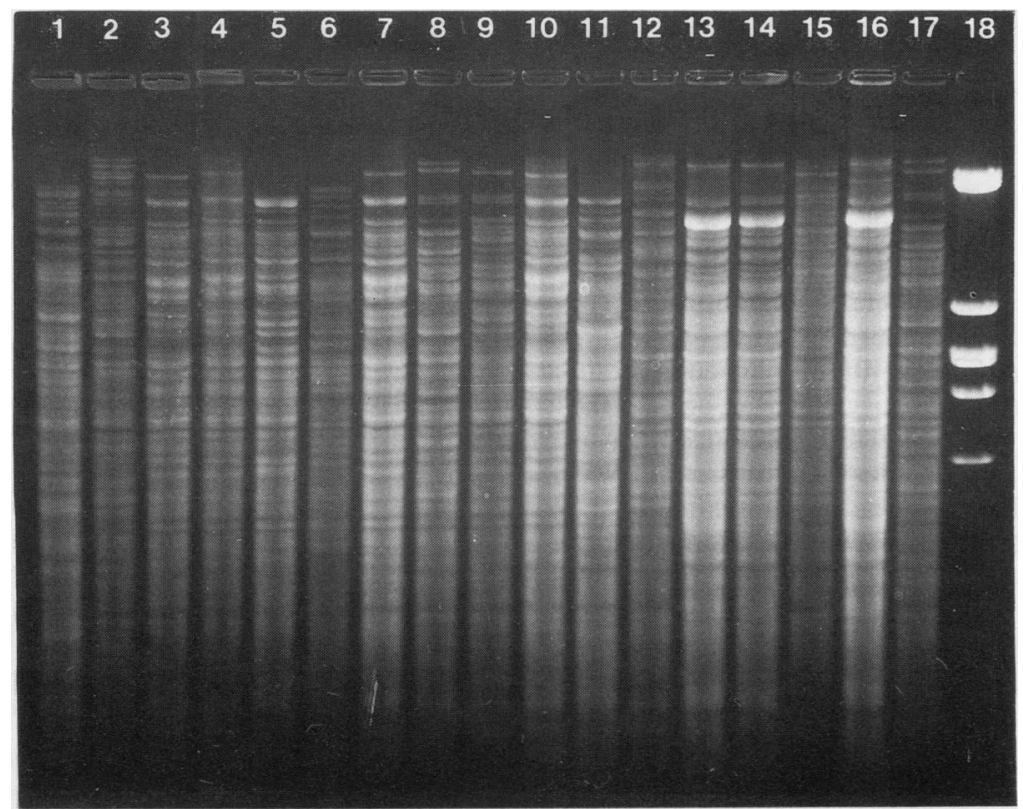

Fig 3 Agarose gel electrophoresis patterns of Hind III digests of chromosomal DNA of 17 C difficile strains (Lanes 1 to 17). Lane 18 represents Hind III digest of $\lambda$ DNA. Lanes represent following isolates (lane number:isolate number): lane 1:46; lane 2:45; lane 3:40; lane 4:35; lane 5:33; lane 6:32; lane 7:31; lane 8:27; lane 9:26; lane 10:25; lane 11:17; lane 12:11; lane 13:7; lane 14:6; lane 15:15; lane 16:4; lane 17:10.

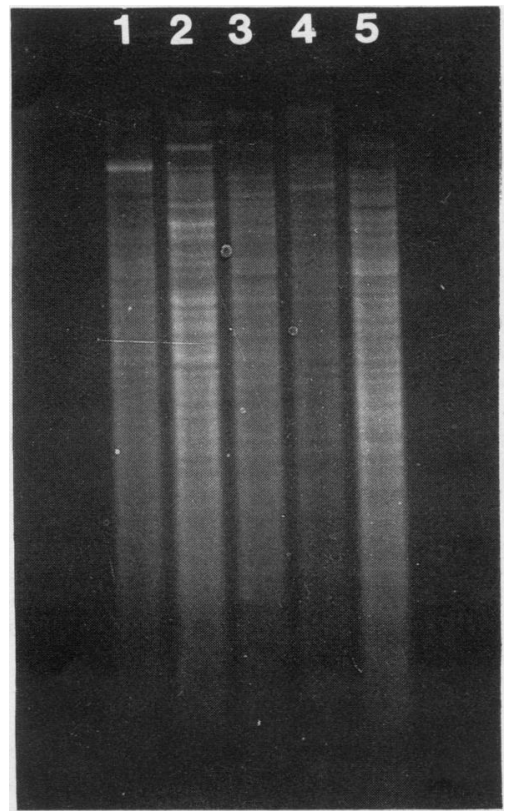

Fig 4 Agarose gel electrophoresis patterns of Hind III digests of chromosomal DNA of $C$ difficile strains with restriction pattern type $A$ (lane 1), B (lane 2), C (lane 3), $D$ (lane 4 ) and E (lane 5 ). method. With respect to discriminating power, restriction endonuclease analysis seems to be superior to other typing methods. Antibiogram typing is not very discriminating, at least not in this study. Another drawback of antibiogram typing for sensitive anaerobic micro organisms is the existence of technical problems associated with this method, which was reflected by our own difficulties and by the discrepancies between the results of different studies using similar techniques. ${ }^{21}$ The same lack of discrimination is to be expected from serotyping, as in a study of 315 strains $99 \%$ could be typed with only six antisera, indicating that many different strains belong to the same serotype. $^{8}$

We were not able to confirm the observation of Delmee, Homel, and Wauters ${ }^{8}$ that sorbitol fermentation is a useful discriminating characteristic of $C$ difficile strains. The continuous distribution of $\mathrm{pH}$ values suggests that most strains are weak fermentors of sorbitol, with only quantitative strain differences, making sorbitol fermentation unsuitable for use as an epidemiological marker. The same results were found for the fermentation of xylose and trehalose (data not shown). The discrepancy between our results and those of Delmee et al cannot be explained by the different broth base that we used; 10 strains tested in thioglycolate broth as used by Delmee et al, ${ }^{8}$ pro- 
duced similar results in peptone yeast extract medium (data not shown). Similar results using peptone yeast extract medium were obtained (data not shown).

Though this study was primarily intended to evaluate this typing method for $C$ difficile, some interesting results were obtained. The colonisation of children in three different wards with the same strain of $C$ difficile indicates that this strain must have been present in the environment in these wards in fairly high numbers for a prolonged period. This is indicated both by the fact that children were colonised with this particular strain throughout the four month survey period and by the fact that this strain was isolated in three neonates as early as the second day of life. That this strain was isolated in three different wards can be related to the transferral of children between these paediatric wards. Another possibility is spread of $C$ difficile by doctors visiting different paediatric wards. The high percentage of children colonised with this particular strain, while only occasionally other strains were isolated, suggests a difference in the ability of different strains to colonise the intestines as already suggested by Delmee et al. $^{8}$ Another interesting phenomenon was the alternating isolation of two different strains of $C$ difficile from one patient (case 10). This patient received oral antibiotics for selective gut decontamination during treatment for leukaemia. The frequent isolation of $C$ difficile from this and similar patients suggests that patients receiving antibiotics for selective decontamination may be especially prone to colonisation by $C$ difficile. The importance of this, previously observed by Rogers et $\mathrm{al}^{23}$ is not yet clear and deserves further study.

These two examples show the suitability of restriction endonuclease analysis for epidemiological studies of $C$ difficile. This method, perhaps in combination with more simple but less discriminating typing methods, facilitates further studies in some aspects of the pathogenesis of $C$ difficile infections, such as mode of transmission or colonising ability, which depend on a highly discriminating typing method.

\section{References}

I Nakamura S, Mikawa M, Nakashio S, et al. Isolation of Clostridium difficile from the feces and the antibody in sera of young and elderly adults. Microbiol Immunol 1981:25:345-51.

2 Viscidi R. Wiley S. Bartlett JG. Isolation rates and toxigenic potential of Clostridium difficile isolates from various patient populations. Gastroenterology 1981:81:5-9.

3 Richardson SA. Alcock PA. Gray J. Clostridium difficile and its toxin in healthy neonates. $\mathrm{Br}$ Med $J$ 1983:287:878.

4 Abeyesundere RL. A ward outbreak of Clostridium difficile enterocolitis. $J$ Infect 1982:5:277-82.

5 Kim K. DuPont HL. Pickering LK. Outbreaks of diarrhea associ- ated with Clostridium difficile and its toxin in day-care centers: evidence of person-to-person spread. $J$ Pediatr 1983;102:376-82

6 Larson HE. Barclay FE. Honour P. Hill ID. Epidemiology of $\Rightarrow$ Clostridium difficile in infants. $J$ Infect Dis 1982:46:727-33.

7 Wust J, Sullivan NM, Hardegger U, Wilkins TD. Investigation of an outbreak of antibiotic associated colitis by various typing methods. J Clin Microhiol 1982:16:1096-101.

8 Delmee M. Homel M. Wauters G. Serogrouping of Clostridium $\frac{\overline{\bar{S}}}{\vec{S}}$ difficile strains by slide agglutination. J (lin Microhiol $\mathbb{Q}$ 1985;21:323-7.

9 Wexler H, Mulligan ME. Finegold SM. Polyacrylamide gel electrophoresis patterns produced by Clostridium difficile. $R e^{\prime} r \vec{O}$ Infect Dis 1984;6:S229-S234.

10 Tabaqchali S, OFarrell S. Holland D, Silman R. Typing scheme for Clostridium difficile: its application in clinical and epidemiological studies. Lancet 1984:i:935-8.

11 Poxton IR, Aronsson B. Möllby R. Nord ('E. Collee J(; Immunochemical fingerprinting of Clostridium difficile strains isolated from an outbreak of antibiotic-associated colitis and diarrhoea. J Med Microhiol 1984:17:317-24.

12 Sell TL, Schaberg DR. Fekety FR. Bacteriophage and bacteriocin typing scheme for Clostridium difficile. J ( $\operatorname{lin}$ Microhiol 1983:17:1148-52.

13 Marshall RB. Wilton BE. Robinson AJ. Identification of Leptospira serovars by restriction-endonuclease analysis. $J$ Med $M$ icrobiol 1981:14:163-6.

14 Bradbury WC, Pearson AD, Marko MA, Congi RV, Penner JL. Investigation of a Campylobacter jejuni outbreak by sero- $\overrightarrow{0}$ typing and chromosomal restriction endonuclease analysis. $J$ Clin Microhiol 1984:19:342-6.

15 Van Ketel RJ. Ter Schegget J. Zanen HC. Molecular epidemiology of Legionella pneumophila serogroup 1. I C lin Microbiol 1984:20:362-4

16 Wiley SH. Bartlet JG. Cultures for Clostridium difficile in stools containing a cytotoxin neutralized by ("lostridium sordelli antitoxin. J Clin Microbiol 1979:6:880-4.

17 Wilson KH, Kennedy MJ. Fekety FR. Use of sodium taurocholate to enhance spore recovery on a medium selective for Clostridium difficile. J Clin Microbiol 1982:15:443-6.

18 Holdeman LV. Cato EP. Moore WEC. Anaerohe laboratory munual. 4th ed. Blackburg: Virginia Polytechnic Institute and State University, 1977.

19 Change Te-Wen. Lanerman M. Bartlett JG. Cytotoxicity assay in antibiotic-associated colitis. $J$ Infect Dis 1979:140:765 -70.

20 National Committee for Clinical Laboratory Standards Proposed reference dilution procedure for antimicrobic susceptibility testing of anaerobic bacteria. PSM 11 . Villanova. oิ Pasadena National Committee for Clinical Laboratory Standards. 1979.

21 Ensminger PW. Counter FT. Thomas LJ, Lubbehusen PP. 윽 Susceptibility, resistance development and synergy of $D$ antimicrobial combinations against Clostridium difficile. ( $u r r$ 음 Microhiol 1982:7:59-62.

22 Dzink J. Bartlett JG. In vitro susceptibility of Clostridium difficile $N$ isolates from patients with antibiotic-associated diarrheit or colitis. Antimicroh Agents Chemother 1980:17:695-8.

23 Rogers TR. Petrou M. Lucas C. et al. Spread of Clostridium N difficile among patients receiving non-absorbable antibiotics for gut decontamination. Br Med J 1981:283:408-9.

Requests for reprints to: Professor DM Maclaren. Department of Medical Microbiology, Research Group for Commensal Infections, Vrije Universiteit. Amsterdam. The Netherlands. 